\title{
Mineral Economics-special issue on the SusMinNor project
}

\section{Foreword}

\author{
Mattia Pellegrini ${ }^{1}$
}

Published online: 1 March 2017

(C) Springer-Verlag Berlin Heidelberg 2017

Raw materials are an essential building block for growth and competitiveness of the European economy. Looking at the metals' value chain alone, more than 11 million jobs in downstream manufacturing sectors depend on the secure supply of metals, equal to $40 \%$ of the jobs and value added from the EU's entire manufacturing sector.

In view of the importance of raw materials to the EU economy, the EU adopted the Raw Materials Initiative, ${ }^{1}$ the aim of which is to secure the supply of raw materials. The initiative is based on three pillars:

1. Fair and sustainable supply from global markets

2. Sustainable supply of raw materials within the EU

3. Resource efficiency and supply of secondary raw materials

In addition, the European Commission has also launched the European Innovation Partnership (EIP) on raw materials, which is a stakeholder platform that brings together representatives from industry, public services, academia, and NGOs. Its mission is to provide highlevel guidance to the European Commission, member

\footnotetext{
${ }^{1}$ European Commission, 2008, “"The Raw Materials Initiative-meeting our critical needs for growth and jobs in Europe," COM (2008) 699; European Commission, 2011, "'Tackling the challenges in commodity markets and on raw materials," COM (2011) 25.
}

Mattia Pellegrini

Mattia.Pellegrini@ec.europa.eu

European Commission, DG Internal Market, Industry, Enterpreneurship and SMES, Resource Efficiency and Raw Materials unit, Brussels, Belgium states, and private actors on innovative approaches to the challenges related to raw materials. The EIP put forward a "Strategic Implementation Plan," which offers a concrete agenda until 2020, including actions on research and innovation coordination, technologies for raw material production, substitution, framework conditions for primary and secondary raw materials production, knowledge and skills, and international cooperation.

Finally, the European Commission is also directing close to 600 million EUR of funds to research projects on raw materials, in the context of its R\&I programme Horizon 2020. ${ }^{2}$ Currently, a call is open on an "EU network of mining and metallurgy regions." The purpose is to create a sustainable EU network of regions dedicated to mining (including exploration), processing, and metallurgy aiming at improving related framework conditions, social aspects, and industry competitiveness.

In July 2016, the European Commission published the first edition of the Raw Materials Scoreboard. The Scoreboard brings together information on raw materials in the global context, competitiveness and innovation, framework conditions for mining, circular economy and recycling, and environmental and social sustainability based on 24 generally accepted indicators.

In the thematic cluster on "Framework conditions for mining" the Scoreboard documents that according to mining company managers, the minerals' policy framework varies considerably. Figure 1 shows the 2014 Fraser Institute's Policy Perception Index and Investment Attractiveness Index for major mining countries. The perception of policy framework conditions

\footnotetext{
${ }^{2}$ Work Programme 2016-2017, SC5-15-2016-2017: Raw materials' policy support actions, see http://ec.europa.eu/research/participants/data/ref/h2020 /wp/2016_2017/main/h2020-wp1617-climate_en.pdf
} 
Fig. 1 Policy Perception Index and Investment Attractiveness Index (based on Fraser Institute Annual Survey of Mining Companies, 2014)

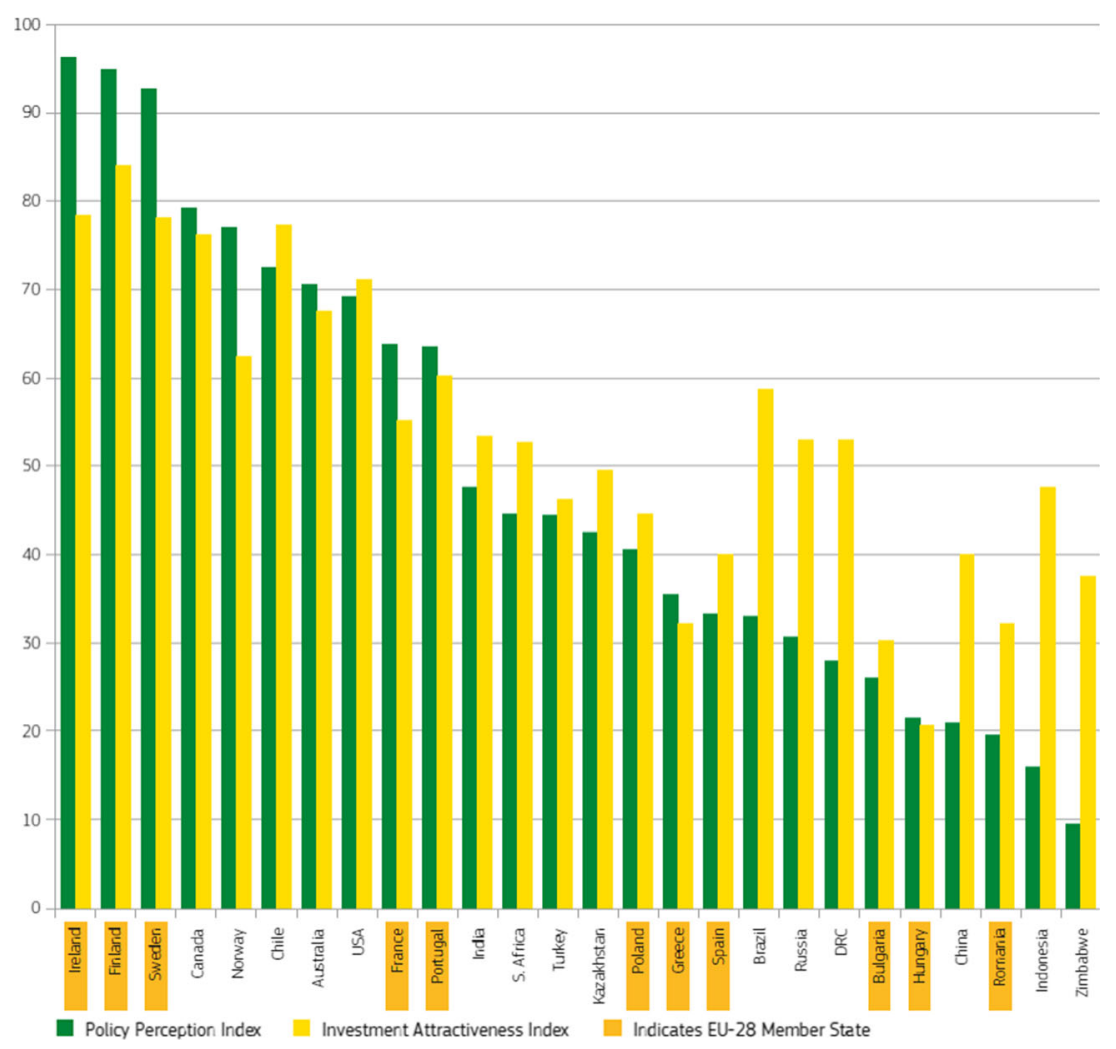

varies significantly in the major raw material supplier countries. Ireland, Finland, and Sweden receive the highest scores (Policy Perception Index between 96 and 92), and Romania is among the least attractive countries (Policy Perception Index $=19$ ). ${ }^{3}$

The Scoreboard further also includes an indicator on "Public acceptance." Public acceptance is a prerequisite for the development of any economic activity. It is linked to the "social license to operate." This refers to the notion that companies need not only government permission to conduct their business but also society's permission based on the trust of the community in which they operate. ${ }^{4}$ For the mining sector, public acceptance is a particular challenge, both for existing mines and for the development of new mining activities. The Scoreboard demonstrates that the general public in countries like Sweden and Finland is twice as likely to believe that mining and oil and gas companies are making efforts to behave responsibly towards society than in some other EU Member States, even if the general figures are still relatively low.

In this regard, it is interesting to see that the EU raw material sectors are taking public concerns about environmental

\footnotetext{
${ }^{3}$ European Commission, European Innovation Partnership on "Raw Materials Scoreboard (2016)," (pp. 61)

${ }^{4}$ European Commission (2016), "Raw Materials Scoreboard" (pp. 61)
}

impacts and community relations seriously and are committed to improving their transparency and corporate social responsibility $^{5}$ (see Fig. 2).

This special issue of Mineral Economics presents the results of the SusMinNor project on "Sustainable mining in northernmost Europe - Lessons learned and practices developed," which aims at improving the understanding of mining's potential contribution to local economies and the implications of mining for sustainable development in the region. SusMinNor is funded by Interreg Nord, which is an EU programme supporting crossborder cooperation in order to strengthen the economic and social development in the northernmost area of the EU (north Norway, north Finland, north Sweden including Sápmi).

The value of the articles in this special edition-most of which deal with the social sustainability and public acceptance of the mining sector-cannot be underestimated. As the EU is highly dependent on raw materials that are crucial for a strong European industrial base, creating the right framework conditions for domestic production is an important pillar to ensure the security of supply. Research on the local impacts of mining and regions is of crucial importance in this regard.

\footnotetext{
${ }^{5}$ Ibidem, pp. 93
} 
Raw materials companies publishing GRI reports in Europe and total world (trend 2000-2014)

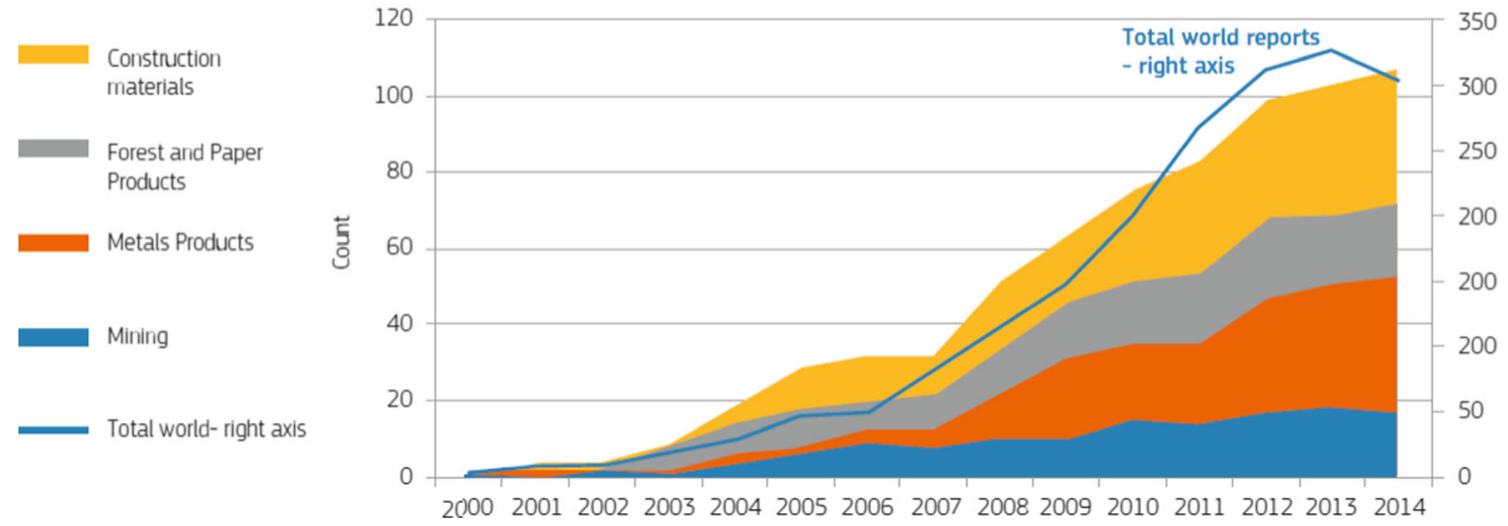

Fig. 2 Number of companies that have joined the Global Reporting Initiative (Europe, 2014)

Interesting links

- Raw Materials Scoreboard: http://bookshop.europa. eu/en/raw-materials-scoreboard-pbET0215541/

- European Innovation Partnership on Raw Materials: https://ec.europa.eu/growth/tools-databases/eip-rawmaterials/en
- Horizon 2020 2016-2017 Work Programme, Societal Challenge 5 on Climate action, environment, resource efficiency and raw materials: http://ec.europa. eu/research/participants/data/ref/h2020/wp/2016 2017 /main/h2020-wp1617-climate_en.pdf 